NBER WORKING PAPER SERIES

\title{
FORECLOSURES, ENFORCEMENT, AND COLLECTIONS UNDER THE FEDERAL MORTGAGE MODIFICATION GUIDELINES
}

\author{
Casey B. Mulligan \\ Working Paper 15777 \\ http://www.nber.org/papers/w15777 \\ NATIONAL BUREAU OF ECONOMIC RESEARCH \\ 1050 Massachusetts Avenue \\ Cambridge, MA 02138 \\ February 2010
}

I appreciate comments by Gary Becker, Kevin Murphy, a number of University of Chicago students, conference participants at the University of Illinois Chicago Campus, and seminar participants at Clemson, Harvard, UCLA, Wisconsin, and the Federal Reserve Bank of New York. I will provide updates on this work on my blog www.panic2008.net. The views expressed herein are those of the author and do not necessarily reflect the views of the National Bureau of Economic Research.

NBER working papers are circulated for discussion and comment purposes. They have not been peerreviewed or been subject to the review by the NBER Board of Directors that accompanies official NBER publications.

(C) 2010 by Casey B. Mulligan. All rights reserved. Short sections of text, not to exceed two paragraphs, may be quoted without explicit permission provided that full credit, including $\odot$ notice, is given to the source. 
Foreclosures, Enforcement, and Collections under the Federal Mortgage Modification Guidelines Casey B. Mulligan

NBER Working Paper No. 15777

February 2010

JEL No. H21,L11,R31

\begin{abstract}
$\underline{\text { ABSTRACT }}$
Federal mortgage modification initiatives, targeting millions of borrowers, are intended to prevent foreclosures of underwater home mortgages. Those initiatives discourage principal reductions in favor of interest reductions, despite the possibility that the former would be a more durable foreclosure prevention tool. The programs also impose marginal income tax rates substantially in excess of 100 percent. Using the framework of optimal income taxation, this paper shows how alternative means-tested modification rules would simultaneously improve collections, efficiency, the number of foreclosures, and their total cost. As a result, lenders have an incentive to foreclose on borrowers deemed modification eligible by the federal programs.
\end{abstract}

Casey B. Mulligan

University of Chicago

Department of Economics

1126 East 59th Street

Chicago, IL 60637

and NBER

c-mulligan@uchicago.edu 


\section{Introduction}

By some measures, U.S. average housing prices have fallen by a third since 2006 and some forecast them to fall further. Prices have fallen more than fifty percent in Las Vegas and Phoenix, and nearly as much in Detroit, Miami and much of California. ${ }^{1}$ As a result, almost 14 million home mortgages nationwide were "underwater" in early 2009: the amount owed exceeded the market value of the collateral. ${ }^{2}$ About one third of home mortgages in Arizona, California, Florida, and Michigan, and more than one half of home mortgages in Nevada, were underwater.

The sudden drop in housing prices is an important reason why, as of early 2009, more than five million homes were already either in foreclosure (lenders were seizing the collateral as a consequence of lack of payment) or their owners were delinquent on their mortgage payments. When foreclosures are motivated by low home values rather than the quality of the match between a homeowner and his home, a foreclosure is inefficient because it requires the homeowner to live elsewhere. The anticipation of foreclosure of an underwater mortgage probably also creates moral hazard in maintaining the house, because the occupant prior to foreclosure has no stake in the home's value. Nonpayment of mortgage obligations are also said to harm the health of the financial system, and thereby the entire economy. It may be no accident that underwater mortgages were prevalent in the Great Depression (Bernanke, 1983), and became so prevalent immediately before this deep recession got started. These are some of the reasons why public policy seeks to reduce foreclosures (Congressional Oversight Panel, 2009, p. 11).

\footnotetext{
${ }^{1}$ National and city-level housing price changes in this paragraph are for the Case-Shiller composite home price index.

${ }^{2}$ http://www.nytimes.com/2009/05/04/opinion/04mon2.html, http://www.reuters.com/article/bondsNews/idUSN2832609020090528. About one in four homes with mortgages were under water by 2009 Q2 (Levy, 2009).
} 
So far, mortgage modification initiatives have been the main way the federal government has sought to reduce foreclosures, especially when those foreclosures are motivated by negative home equity (Congressional Oversight Panel, 2009, p. 4). In 2008, the Federal Deposit Insurance Corporation (FDIC), Federal National Mortgage Association (Fannie), and the Federal Home Loan Mortgage Corporation (Freddie) all announced debt forgiveness or "loan modification" formulas. The Obama Treasury Department continued this work with its "Home Affordable Modification Program" (HAMP) as part of its "Making Home Affordable Initiative,"3 which replaced the Fannie and Freddie programs. HAMP alone targets 3-4 million mortgages.

As compared to the several millions of mortgages underwater, delinquent, and in the foreclosure process, less than two million mortgages have actually been modified or otherwise had their payments adjusted through the third quarter of 2009. ${ }^{4}$ Moreover, observers lament that most of those modifications adjust interest payments without reducing principal, and thereby may only delay foreclosures rather than genuinely preventing them. ${ }^{5}$ It also seems that borrowers are uncertain about the modification process: the degree to which their payments will be reduced, whether lenders will deem them eligible, and when they can expect a modified mortgage to be in place.

This paper shows how all of these outcomes, and more, may be a direct result of stark incentives created by the FDIC and HAMP programs (hereafter jointly referenced as $\mathrm{FH}$ ) and their practice of targeting the ratio of housing expenses to borrower income. ${ }^{6}$ Section II shows how, as designed, the programs make it impossible to both write down principal and offer modification to a wide range of borrowers. In other words, the programs have unnecessarily manufactured a tradeoff between the number of foreclosures prevented in the short term and the durability of those foreclosure prevention efforts.

The FH programs offer modifications on the basis of borrower income reported to the IRS. In many instances, the implicit marginal income tax rates far exceed 100

\footnotetext{
${ }^{3}$ Making Home Affordable was originally announced in February 2009 as the "Homeowner Affordability and Stability Plan" (HASP). The FDIC's initiative was called "Streamlined Mortgage Modification."

${ }^{4}$ Office of Thrift Supervision (2009a, p. 18; 2009b, p. 6).

${ }^{5}$ Geanakopolos and Koniak (2009) and COP (2009)

${ }^{6}$ HUD has another program with a fundamentally different incentive structure (COP, p. 81).

Understandably, very few mortgages have been modified under the HUD program, so consideration of it is omitted from this paper.
} 
percent. Principal reductions are said to be the more durable foreclosure prevention tool, but they can create marginal income tax rates as large as 400 percent (sic). Section III uses the marginal tax rate findings and the framework of optimal tax theory to prove that alternative modification rules could simultaneously reduce foreclosures and their cost, increase collections, and increase efficiency. This framework allows me to consider a wide range of income supply conditions - including the case in which the supply of income does not respond to incentives - yet the results proven hold throughout that range.

Taken literally, the FH programs create such poor incentives that one is left wondering whether lenders would ever enforce them: that is, willingly make modifications to borrowers deemed eligible by $\mathrm{FH}$, and in the amounts required to hit the FH income share target. Section IV explains how lenders have an incentive to randomly foreclose on borrowers deemed modification-eligible by $\mathrm{FH}$, because the resulting uncertainty faced by borrowers would discourage them from fully responding to the program's massive marginal income tax rates. As compared to FH programs that were fully enforced, the result is a higher ratio of foreclosures to modifications, but more collections and a more efficient supply of income. Section V concludes.

Kahn and Yavas (1994) is an early paper modeling foreclosures as the "outside option" in a mortgage renegotiation. This aspect of renegotiation was studied further by Livshits et al (2007), White and Zhu (2008), but still considering borrower income as an exogenous characteristic - and therefore not studying the tradeoff between foreclosures and moral hazard in the labor market. Han and $\mathrm{Li}$ (2007) consider the combined wealth and substitution effects of mortgage modification on labor supply, but do not attempt to separate them or calculate a labor market deadweight cost of modifications. Grochulski (2008) models personal bankruptcy negotiations as a mechanism design problem akin to Mirrlees (1971). None of these consider the FH programs affecting millions of borrowers during this recession. Mulligan (2009) considers a stylized version of the economic environment studied here - that paper assumes full enforcement, less borrower heterogeneity, and less detail about mortgage contracts - for the purpose of characterizing the mortgage modification rules that would maximize collections and thereby the rules preferred by lenders. 


\section{The Budget Set of a Borrower Facing the FDIC-HAMP Modification Guidelines}

\section{II.A. Underwater Arithmetic}

Consider a mortgage loan with contractual payments in the constant amount $h$ remaining from year zero until year $M>5$. Assuming payments are expected to be made as contracted, its present value as of year $t$ is $h R_{M, t}$, where $R_{M, t}$ is the present value of $\$ 1$ paid in each of the years $t, t+1, \ldots M$, from the perspective of year $t$ (except when needed, hereafter I suppress the second element of the time subscript: $R_{M}$ refers to the time 1 present value of $\$ 1$ paid in years 1 through $M$ ).

Let $H_{t}$ be the market value of the loan's collateral in year $t$. Ignoring for the moment any foreclosure costs borne by the borrower or lender and any difference between the rates at which borrower and lender discount cash flows, a foreclosure at date 1 creates a transfer from lender to borrower with present value $h R_{M}-H_{1}$, as compared to the alternative of full contractual payments made for the life of the loan. Hereafter, I use $b=h R_{M}-H_{1}$ to denote the "underwater" or unsecured amount of the mortgage as of year 1. Since a borrower can always avoid foreclosure by making the contractual payments, foreclosures during year 1 are expected to be much more common when loans are "underwater" $b>0$ (that is, "home equity is negative"), because foreclosure on an underwater loan can create this windfall for the borrower. ${ }^{7}$

This paper examines the economic incentives created by a "loan modification" occurring in year 1 , perhaps to be followed by additional modifications in later years. In other words, time is normalized so that year 0 (or "base year") is the year prior to modification, year 1 is the year of modification, and years $2,3, \ldots M$ are the years

\footnotetext{
${ }^{7}$ Note that "inability to pay" is probably not enough by itself to create a foreclosure (Foote et al, 2009, footnote 3 ), because a homeowner unable to pay but with positive home equity may want to sell his home to pay the loan (and thereby retain his home equity) rather than invite foreclosure. Liebowitz (2009) finds that negative equity was a more important factor than unemployment in causing the foreclosures that occurred in the second half of 2008. Geanakopolos and Koniak (2009) find that foreclosures are "stunningly sensitive" to the amount of home equity. In any case, the FDIC and Treasury have represented their programs as solutions to foreclosures motivated by negative equity, and not foreclosures that result from unemployment spells (Congressional Oversight Panel, 2009, p. 4). As noted below, the programs consider borrowers with the lowest incomes to be ineligible for modification.
} 
thereafter. A year 1 loan modification - a change the contractual loan payments reduces the borrower's gain from year 1 foreclosure only if the modified payments have a lesser year 1 present value than the contractual payments. The year 1 modification reduces the borrower's gain (if any) from foreclosure in year $t>1$ only if the payment changes reduce the year $t$ present value of payments to be made in years $t$ through $M$. Thus, of primary interest in the economic analysis of modification is the timing of payment reductions, and the factors that determine the amount to be reduced.

\section{II.B. FDIC-HAMP Guidelines}

According to the FH guidelines, year 1 modifications should achieve three objectives:

(1) income share target: a combined housing expense (principal, interest, taxes, and insurance) during each of the years $1-5$ that is no greater than $\mu$ times borrower income in year $0, y_{0}{ }^{8}$

(2) NPV test: the post-modification loan has value at least as great as the value of the collateral to the lender, ${ }^{9}$ and

(3) borrower option: Borrowers are free to stay with their obligations under the original mortgage contract (including its foreclosure provisions), and free to request modifications in the future.

The FDIC and HAMP programs differ in terms of the income share target $(\mu=38 \%$ and $31 \%$, respectively). ${ }^{10}$ In principle, FDIC and HAMP have the same NPV test, although only FDIC has publicized the formula for its NPV test (Congressional Oversight Panel, 2009, p. 85: hereafter, “COP”).

\footnotetext{
${ }^{8}$ FDIC's early plan said "Modifications would be designed to achieve sustainable payments at a 38 percent debt-to-income ratio of principal, interest, taxes, and insurance.” (FDIC, 2008a). See also U.S. Treasury (2009a, pp. 2-3). FDIC (2008b, p. 8) indicates that homeowners' association dues are also included in "housing expenses."

${ }^{9}$ FDIC (2009), Department of Treasury (2009c). Congression Oversight Panel (2009, p. 47) explains "If the NPV of the modification scenario is greater [than the NPV of foreclosure], then the servicer must offer to modify the loan."

${ }^{10}$ More recently, the FDIC has used a mix of 31 percent and 38 percent targets (FDIC, 2008b).
} 
The most common modification reduces "interest" in the sense that it reduces payments during years 1 - 5 and leaves payments after year 5 unchanged. ${ }^{11}$ A second possibility is that principal is written down in the sense that payments in all years $1-M$ are reduced by the same proportion, thereby reducing foreclosure incentives in all years. ${ }^{12}$ Let $\delta$ denote the proportion by which principal is written down, and $\Delta$ be the absolute amount by which payments during years $1-5$ are reduced beyond their reduction (if any) due to reduced principal.

Formally, a date 1 modification reduces the present value of mortgage payments by $\delta h R_{M}+\Delta R_{5}$. The guidelines require:

$$
\begin{gathered}
(1-\delta) h-\Delta+T \leq \mu y_{0} \\
\delta h R_{M}+\Delta R_{5} \leq h R_{M}-H_{1} \equiv b
\end{gathered}
$$

where $h$ is the contractual mortgage payment (principal and interest), not including the amount $T$ of taxes and insurance. The inequality (1) is the income share target, in which year $1-5$ housing expenses have been modified from $h+T$ to $(1-\delta) h+T-\Delta$. The inequality (2) is the NPV test. ${ }^{13}$

As part of the NPV test, lenders can consider the probability that borrowers will default on, or request further modification of, the modified loan. To the degree that they consider these possibilities, the parameters $R_{5}$ and $R_{M}$ in the NPV test above should be interpreted to include those effects. ${ }^{14}$

\footnotetext{
${ }^{11}$ In principle, such modifications could leave payments after year 5 unmodified, although the U.S. Treasury (2009a, pp. 2-3, emphasis added) has said "[the] lower interest rate must be kept in place for five years, after which it could gradually be stepped up to the conforming loan rate in place at the time of the modification.”

${ }^{12}$ A third possibility is that reductions in payments for years $1-5$ are at least partially offset by increases in payments after year 5, as with an increase in the loan's amortization period. In this third case, foreclosure incentives after year 5 (and perhaps even as early as year 2) can be increased by modification, and little is done to improve foreclosure incentives in year 1 . Perhaps this is why increases in payments after year 5 are rarely used in practice and are rarely advocated even by those who disagree with current foreclosure policies. Following Kahn and Yavas (1994), my paper does not consider modifications that fail to affect the present value of payments.

${ }^{13}$ To the degree that the collateral has a different market value than its value to the lender, $H_{1}$ should be interpreted as value to the lender for the purpose of these formulas.

${ }^{14}$ If, for example, the lender anticipated borrowers to be modified again in year 3, then the appropriate parameter for the NPV test would be $R_{3}$ (rather than the $R_{M}$ and $R_{5}$ shown above).
} 


\section{II.C. Marginal Tax Rates and the Range of Eligible Incomes}

Some borrowers have incomes sufficiently large, or contractual mortgage payments sufficiently small, that the guideless can be met with no modification. For the others, the guideline amount modified is (hereafter, I suppress the time subscript on base year income):

$$
\begin{aligned}
& \frac{R_{5} R_{M}}{\rho R_{5}+(1-\rho) R_{M}}(h+T-\mu y) \leq \delta h R_{M}+\Delta R_{5} \leq b \\
& \rho \equiv \frac{\delta h R_{M}}{\delta h R_{M}+\Delta R_{5}}
\end{aligned}
$$

As noted, modifications can vary in the degree to which principal rather than interest is modified; the parameter $\rho \in[0,1]$ denotes the amount of the principal reduction, expressed as a share of the total modification amount. The inequalities (3) put upper and lower bounds on the amount modified: the upper bound comes from the income share target (1) and the lower bound from the NPV test (2).

If year 0 borrower income $y$ is too low, the above interval may not exist, in which case no modification amount can both meet the income target and satisfy the NPV test. Define the modification-eligible income interval to be the range of income $y$ in which income is high enough that the income share target can be met without failing the NPV test (2), but low enough that some modification is required in order to meet the income share target (1):

$$
y \in\left[\max \left\{0, \frac{h+T}{\mu}-\left(\frac{\rho}{R_{M}}+\frac{1-\rho}{R_{5}}\right) \frac{b}{\mu}\right\}, \frac{h+T}{\mu}\right]
$$

I refer to the lower income bound as the "minimum income threshold."

Proposition 1 The greater the share $\rho$ of modification in the form of principal reduction, the narrower the range of eligible incomes.

Proof Follows immediately from the set (4) and that $R_{M}>R_{5}$ (that a dollar paid for 5 years is worth less than a dollar paid for more than five years). 
Several observers have commented that much of the modification activity under FH has reduced interest payments for years $1-5$, rather than writing down principal, and thereby does nothing to the foreclosure incentives in years 6 and later (and does little to the foreclosure incentives in years shortly before year 6). ${ }^{15}$ However, under the practice of targeting the income share during the years immediately after modification, Proposition 1 shows how writing down principal may do little to reduce present foreclosure incentives because the range of eligible incomes would be narrower than it is when interest is modified. ${ }^{16}$

Proposition 2 If the amount $b$ of negative home equity is greater, the minimum eligible income is lower and the range of eligible incomes is wider.

For any given amount $b$ of negative equity, the present value $x(y)$ of the modified payments satisfying the NPV test and income share target is a piece-wise linear function of base year income $y$ :

$x(y)=\left\{\begin{array}{c}b-\left(\frac{h+T}{\mu}-y\right) \frac{\mu R_{5} R_{M}}{\rho R_{5}+(1-\rho) R_{M}} \quad \text { if } y \in\left[\max \left\{0, \frac{h+T}{\mu}-\left(\frac{\rho}{R_{M}}+\frac{1-\rho}{R_{5}}\right) \frac{b}{\mu}\right\}, \frac{h+T}{\mu}\right] \text { otherwise } \\ b\end{array}\right.$

where (5) assigns no modification to incomes outside the eligible range. Proposition 3 examines the slope of this function:

Proposition 3 The marginal dollar of income earned by a modification-eligible borrower reduces the value of modifications required to meet the income target, and at a rate that

\footnotetext{
${ }^{15}$ COP, 2009, p. 4.

${ }^{16}$ HAMP gives loan servicers the option to reduce principal before reducing interest (U.S. Treasury, 2009b, p. 8), but the FDIC's protocol specifies that interest be reduced before principal (FDIC, 2008b).

Proposition 1 illustrates how the basic incentives of the income share target and NPV test would encourage modifications of interest rather than principal, even if the FDIC protocol were changed to allow principal be reduced before interest.
} 
likely exceeds one. This "FH marginal income tax rate" increases with the share $\rho$ of modification that is principal reduction.

Proof The marginal income tax rate is the derivative of the modification lower bound with respect to $y$, discounted back from the modification year (1) to the income year (0):

$$
M T R=\frac{1}{1+r_{0}} \frac{\mu R_{5} R_{M}}{\rho R_{5}+(1-\rho) R_{M}} \in\left[\frac{\mu}{1+r_{0}} R_{5}, \frac{\mu}{1+r_{0}} R_{M}\right]
$$

where $r_{0}$ is the one period rate of interest for discounting cash flows from year one to year zero. Recall that $R_{5}$ is the present value of a dollar paid in five consecutive years: at a six percent annual interest rate and $\mu=31 \%, \mu R_{5} /\left(1+r_{0}\right)=131 \%{ }^{17}$ For a loan terminating in year 25, the marginal tax rate under principal reductions would be $\mu R_{M} /\left(1+r_{0}\right)=396 \%$ ! These marginal tax rates are larger still under the FDIC income share target of $\mu=38 \%{ }^{18}$

For a modification that is expected to be mortgage's the final modification, a marginal dollar earned in the base year raises mortgage payment obligations by 31 cents in each of the following five years, if not beyond. If, say, 2009 income were used to calculate the payment meeting the income share target for the years 2010-14 and the interest rate were zero, then the marginal tax rate would be at least 155 percent for 2009 (5 times the formula's 0.31 limit on the payment to income ratio, plus any effect of base year income on payment obligations after year five). At the annual interest rate of 6

\footnotetext{
${ }^{17}$ To the degree that year five modifications automatically create smaller modifications in years later than five in order to prevent interest payments from adjusting too quickly, $R_{5}$ should be augmented to include the additional terms, and therefore be greater than calculated above. See Appendix I for marginal tax rates calculated for longer modification horizons.

${ }^{18}$ More recently, the FDIC has used a mix of 31 percent and 38 percent targets (FDIC, 2008b), which results in various marginal income tax rates over the eligible income range. The resulting marginal tax rates can be somewhat less than they are with HAMP, but typically still more than 100 percent.
} 
percent used in the proof, the year zero marginal income tax rate is between 131 and 396 percent. $^{19}$

The income share target is based on the borrower's gross income prior to the modification, and borrower's federal personal income tax return is the most important document for verifying this income. ${ }^{20}$ The payments specified by a modified loan are set in dollars (of much the same form as specified in the original mortgage contract), and is not adjusted for the borrower's income in years after the modification occurs. Future modifications to the loan may occur, but (assuming the program exists in the future) are at the borrower's discretion. Thus, a borrower whose income grows after the modification will not have his payments adjusted upward as a result of that growth: the marginal tax rate imposed by a year 1 modification on incomes earned in years 2 and following is zero.

In some cases, repeated modifications may be expected, with the next one occurring in less than five years. In this case, the parameters $R_{5}$ and $R_{M}$ in the proposition's MTR formula should be replaced by the present value of a dollar paid in each year from the present until the year prior to the next modification. The marginal tax rate on year zero income could be as small as $\mu R_{1} /\left(1+r_{0}\right)$ (about 30 percent) in such cases, but even then the marginal tax rate of $\mu R_{5} /\left(1+r_{0}\right)$ applies to income earned in the year prior to the final modification, due to the anticipation that the final modification will be reducing (at least) five years of payments. ${ }^{21}$

Propositions 1 and 3 are illustrated by examining the geometry of the borrower's budget set that is consistent with the income share target and the NPV test. Consider a consumer who, in each year, has income that can be spent on mortgage payments and expenditures on items other than mortgage payments. Let $a$ denote the year 0 present value of his income stream from years 1 and forward, plus the value of any assets (other than the collateral) he may have. If he pays his mortgage in full, the present value of resources $c$ available for expenditures other than future mortgage payments is:

\footnotetext{
${ }^{19}$ Appendix I shows marginal income tax rates for various horizons and discount rates.

${ }^{20}$ FDIC (2008b, Appendix).

${ }^{21}$ Some affected borrowers may not have anticipated that they would face a marginal tax rate in excess of $100 \%$. However, given that they can request another modification in the future, it is likely that they will someday experience a year in which their marginal tax rate is both in excess of $100 \%$, and understood to be so.
} 


$$
c=a-\frac{b}{1+r_{0}}+y
$$

If instead he is eligible and willing for a year 1 modification, then his present value budget constraint is (8):

$$
\begin{aligned}
& c=a-\frac{b}{1+r_{0}}+(1-M T R) y+M T R \frac{h+T}{\mu} \\
& y \in\left[\max \left\{0, \frac{h+T}{\mu}-\frac{b}{1+r_{0}} M_{T R}^{-1}\right\}, \frac{h+T}{\mu}\right]
\end{aligned}
$$

Figure 1 displays this budget set in the $[-y, c]$ plane. Consider first the allocation $X$ in which the borrower has no income (in year zero) and consumes the amount $a-b$ while making full mortgage payments. At the allocation $Z_{0}$, the mortgage is written down so that it is no longer underwater; the distance between $X$ and $Z_{0}$ is the amount underwater, $b$. The allocation $Y$ indicates the amount of income that equals (full housing expenses) $/ \mu$ (that is, full housing expenses are equal to 31 percent of income under the HAMP rule). Thus, no allocation to the left of $Y$ is eligible for modification under the FH guidelines.

For the moment, consider only modifications made by reducing interest (no principal reduction). At allocation $Y$ in Figure 1, the present value of mortgage payments falls $\mu R_{5} /\left(1+r_{0}\right)$ (about \$1.31) for each dollar that income is reduced. Because consumption is income minus mortgage payments, consumption therefore increases by $\mu R_{5} /\left(1+r_{0}\right)-1$ (about \$0.31) for each dollar that income falls. The income share target therefore creates an upward sloping budget constraint, at least for incomes near and below the income corresponding to allocation $Y$. The upward slope would be even steeper if modifications were made by reducing principal.

Suppose for the moment that the budget constraint's upward slope continued to the point where income is zero, thereby eliminating all housing payments for five years. In most cases, this would cause the present value of the modified mortgage's payments to 
be significantly less than the home's market value, ${ }^{22}$ and thereby fail the NPV test. Thus, Figure 1 indicates the allocation $W_{0}$ where the income earned is such that exactly $b$ must be written down in order to meet the income share target (the dashed line through $W_{0} Z_{0}$ is parallel to the segment $O X$ ). Year zero income at allocation $W_{0}$ (hereafter, the "zerocollection point”) is $\frac{h+T}{\mu}-\frac{b}{1+r_{0}} M T R^{-1}$, the minimum income threshold.

When it comes to the tradeoff between year 0 income and non-mortgage expenditures, the source of modification funds - principal versus interest reductions matters because the principal reductions create a marginal tax rate $\left(\mu R_{M} /\left(1+r_{0}\right)\right)$ that is even higher than the marginal tax rate $\left(\mu R_{5} /\left(1+r_{0}\right)\right)$ created by interest reductions. Figure 2 compares the budget set in the two cases. The budget constraint with interest reductions is shown as a dashed line, and with principal reductions as a solid line. With principal reductions, the allocation $W_{1}$ on the margin of passing the NPV test is further to the left in the figure than the corresponding zero-collection allocation $W_{0}$ with interest reductions, which means that the minimum income threshold is larger with principal reductions than with interest reductions. ${ }^{23}$

\section{FDIC-HAMP's Potential for Stemming Fo reclosures, Collecting Payments, or Enhancing Efficiency}

\section{III.A. Borrower Reactions with Exogenous Base Year Incomes}

Federal law requires many, although not all, modified mortgages to follow either the FDIC or HAMP guidelines. ${ }^{24}$ The purchasers of mortgages owned by failed banks are required to modify mortgages according to the FDIC guidelines (COP, 2009, p. 84). Citi agreed to use the FDIC formula as a condition to its November 2008 bailout (Aversa, 2008). Servicers of Fannie Mae or Freddie Mac mortgages are obligated to participate in

\footnotetext{
${ }^{22}$ A mortgage with 25 years remaining and rate fixed at six percent has about one third of the present value of its remaining payments come due during the first five years.

${ }^{23}$ An adjustment to the income share target that would put it on a sliding scale (that is, setting the income share target as a constant plus a term inversely proportional to income, rather than merely a constant as with FH) would also change the marginal tax rate and have the comparative statics shown in Figure 2. I return to this point later when considering alternatives to the FH formula.

${ }^{24}$ Even if guidelines were not enforced, and analysis of their effects under full enforcement is a helpful first step toward understanding their actual effects. Section IV of this paper drops the assumption of full enforcement.
} 
HAMP for their Fannie Mae and Freddie Mac mortgages. Participants in TARP programs initiated after February 2, 2009 are required to take part in mortgage modification programs consistent with Treasury standards.

Regardless of whether he is eligible for modification, a homeowner always has the option to stop paying his mortgage. Although state laws are somewhat different, to a good approximation the worst case scenario for a homeowner who stops paying is that he can no longer own or occupy the house, and may suffer a reduction in his credit rating that might raise his costs of future borrowing. I left $m$ denote the combined foreclosure costs of these events ( $m$ is for "moving"). Foreclosure costs include moving costs, the moral hazard related to maintenance (created when a home's occupant is not its owner), and lost access to credit markets. ${ }^{25,26}$ Foreclosure costs vary among borrowers: I let $G(m$; $\gamma$ ) denote the cumulative distribution of those costs, which may depend on a vector of borrower characteristics $\gamma$. A foreclosure would be efficient for a borrower with a negative foreclosure cost, and this paper is about the role of mortgage modification in preventing foreclosures, so for simplicity I assume that all borrowers have nonnegative foreclosure costs. ${ }^{27}$

I assume that a borrower must bear the foreclosure cost $m$ unless either he pays the full amount $b$, or is offered (and accepts) modified payments with present value $x$, of the unsecured part of his mortgage. The FH programs specify the value $x(y)$ of modified payments as a specific piece-wise linear function of income $y$ and negative equity $b$ :

\footnotetext{
${ }^{25}$ Because the mortgage is assumed to be under water, I do not distinguish between foreclosure, "walking away," and "deed in lieu of foreclosure." I refer to all three as "foreclosure" and assume that they result in the payment of deadweight "foreclosure costs."

${ }^{26}$ I model foreclosure costs as if they are entirely paid by borrowers. This is just a normalization, achieved by defining the amount of negative equity $b$ to be the par value of the mortgage minus the value of the home to the bank in the case of foreclosure.

${ }^{27}$ Moving costs may be expected to decline over time, for example, as family circumstances change. A full dynamic model of the moving decision is beyond the scope of this paper, but the moving cost $m$ can interpreted as an average over the modification horizon, and therefore would be low for a family that expects to soon outgrow its current house.
} 


$$
\begin{aligned}
& x(y)=\left\{\begin{array}{c}
b-\left(1+r_{0}\right)\left(\frac{h+T}{\mu}-y\right) M T R \quad \text { if } y \in\left[\max \left\{0, \frac{h+T}{\mu}-\frac{b}{1+r_{0}} M T R^{-1}\right\}, \frac{h+T}{\mu}\right] \\
b \\
\text { otherwise }
\end{array}\right. \\
& M T R \equiv \frac{\mu R_{5} R_{M}}{\rho R_{5}+(1-\rho) R_{M}} \frac{1}{1+r_{0}}
\end{aligned}
$$

where MTR is the constant rate at which the modified payment increases with income (thus, payment modification is said to be "means-tested"), in the range of eligible incomes. The borrower chooses the modified payment or foreclosure, whichever has the

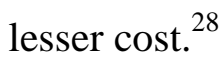

Suppose for the moment that the modification formula did not affect borrower behavior, except for his decision of whether to invite foreclosure. In this case, lender collections from borrowers with characteristics $\gamma$ resemble a textbook monopolist's revenue because lenders face a tradeoff between the unsecured amount $x(\gamma)$ to be repaid

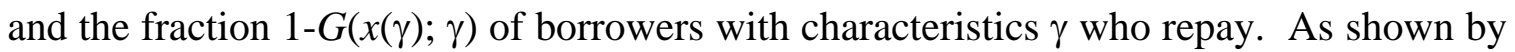
Figure 3's monotone curve, the mirror image of the foreclosure cost CDF illustrates the tradeoff because it maps (the present value of) modified payment amounts on the vertical axis to the fraction of borrowers on the horizontal axis who would prefer that payment amount to their foreclosure cost. In other words, the choice of repayment amount is a choice of a point on that "demand curve."

From this perspective, means-testing makes some sense because base year income $y$ may be correlated with foreclosure costs. ${ }^{29}$ For example, foreclosure costs include costs of nonmarket time and hassle, and high income individuals may place a greater absolute value on future credit market access, because they expect their future credit market transactions to be of greater dollar amounts. However, even if base year income $y$ were the only observable proxy for foreclosure costs and were not affected by the modification formula, Proposition 4 proves that the $\mathrm{FH}$ formulas do not optimize any

\footnotetext{
${ }^{28}$ A borrowing constraint would tend to increase the rate at which borrowers discount future cash flows, and create a gap between discount rates for borrower and lender. Appendix I offers some quantitative analysis of the former, showing that marginal tax rates are expected to exceed 100 percent even for borrowers who discount much more than six percent per year.

${ }^{29}$ Mulligan (2009) places some additional structure on the unobserved heterogeneity among borrowers and finds that collections are maximized by imposing a strictly positive marginal tax rate on borrowers that are eligible for mortgage modification.
} 
objective function that is monotone in collections, foreclosures, and aggregate foreclosure costs:

Proposition 4 Taking the distribution of borrowers' base year incomes as given, there exists a means-tested modification rule satisfying the NPV test that (a) collects more revenue, (b) prevents more foreclosures, AND (c) creates lesser aggregate foreclosure costs than the FH rule.

Proof (i) Among borrowers with the same base year income $y$, collections, foreclosures, and foreclosure costs are:

collections $=[1-G(x ; y)] x$

foreclosures $=G(x ; y)$

foreclosure costs $=\int_{0}^{x} z d G(z ; y)$

For any monotone objective that has these outcomes as arguments, there exists a present value $x^{*}$ of modified payments that maximizes it with respect to $x$ subject to the constraint $x \in[0, b]$. Because $x^{*} \geq 0$, the NPV test is satisfied.

(ii) Now consider the relationship $x^{*}(y, b)$ across borrowers with different base year incomes. $x^{*}$ varies with $y$ because the foreclosure cost distribution does. It varies with $b$ only because of the constraint $x \leq b$. Thus, the amount $b$ underwater would not affect the identity of borrowers who receive the maximum modification under the optimal rule $x^{*}(y, b)$.

(iii) Under the FH rules, the borrowers receiving the maximum modification are those earning exactly the minimum income threshold, which depends on the amount $b$ underwater. Thus, neither FDIC nor HAMP maximize the objective.

Foreclosures and foreclosure costs are monotone increasing in $x$, so Proposition 4 would be trivial without regard for collections (all inefficient foreclosures could be avoided merely by writing down each mortgage to its collateral value). More generally, recall that the FH modification specifies a minimum income threshold below which borrowers are not eligible for modification (in particular, not eligible for the maximum 
modification offered to borrowers who earn exactly the threshold), and the threshold falls with the amount $b$ underwater. Now consider those borrowers with base year income $y^{\prime}$ that coincides with the threshold if the amount under water were $b^{\prime}>b^{\prime \prime}>0$. Suppose further that the modification $x(y)=0$, which would be offered by FH if $y^{\prime}$ happened to be the minimum income threshold, did maximize the objective (depending on collections, foreclosures, and foreclosure costs among borrowers with income $y$ ). Then $x(y)=0$ should maximize the same objective for both underwater amounts $b^{\prime}$ and $b^{\prime \prime}$, yet $\mathrm{FH}$ would offer $x(y)=0$ if the underwater amount were $b^{\prime}$ and $x(y)=b^{\prime \prime}$ if the underwater amount were $b^{\prime \prime}$.

\section{III.B. Borrower Reactions with Endogenous Base Year Incomes}

It is possible that a significant number of borrowers understand that their income affects their position in a future modification. Even if borrowers were surprised in, say, 2008 that mortgages would be modified according to borrower income, they still had the option to delay their modification until 2009, 2010, or even later, and in the meantime supply income in a way that reflected all known costs and benefits, including the benefits of future mortgage modification. ${ }^{30}$

To model this behavioral response, I assume that borrowers view the supply of income as a bad, and the available of resources $c$ for expenditure as a good, according to the utility function $u(c, y ; \gamma) . \quad \gamma$ is a vector of borrower characteristics that determine, among other things, the marginal rate of substitution between $c$ and $y$. The marginal rate of substitution is a strictly positive continuous of function of $\gamma$. The cross-borrower distribution of the characteristics $\gamma$ and the foreclosure cost $m$ is continuously differentiable on the set $\Gamma$, and has strictly positive density everywhere on the interior of $\Gamma$, and zero density outside the set $\Gamma$. To simplify the exposition, I assume that the set $\Gamma$

\footnotetext{
${ }^{30}$ A large literature has documented behavioral responses to various means-tested benefits (Moffitt, 2003), and most of those pay benefits on the basis of lagged incomes. For example, the food stamp program has a monthly reporting form in some states (Neighborhood Legal Services Association, 2009), and a quarterly reporting form in other states (Legal Services of Northern California, 2008), that determine food stamp allotments approximately two or three months later. In public pension programs, beneficiary behavior can affect benefits over a several year horizon (Gruber and Wise, 1999).
} 
is broad enough that the support of the distribution of efficient incomes is wider than the eligible income range. ${ }^{31}$

Note that these assumptions are consistent with the idea that borrowers are unwilling to deviate from an "optimal" or "habitual" income - that unwillingness can be represented in terms of the curvature of indifference curves, without denying that the marginal rate of substitution between $c$ and $y$ is positive. These assumptions are weaker than typically assumed in the optimal taxation literature ${ }^{32}$ and consistent with a positive, but arbitrarily small, elasticity of income supply to incentives. Thus, the findings below could well describe actual responses to the FH modification rule, even if the rule were known to have only a small effect on the distribution of base year income.

If borrowers are free to choose any point on their budget set in the $[-y, c]$ plane, then the FH budget set might was well be nothing more than the single zero-collection point $W_{0}$ added to the budget set absent modification, because the other points in the $\mathrm{FH}$ budget set are strictly dominated by the zero-collection point (recall Figure 1). Thus, outcomes under FH consist of borrowers located at the zero-collection point $W_{0}$ plus borrowers who make the same choice as they would without FH.

Let $\Omega\left(W_{0}\right)$ denote the set of borrowers who weakly prefer modification to their next best alternative (i.e., either paying in full or inviting foreclosure). Formally,

$$
\begin{aligned}
\Omega\left(W_{0}\right) & \equiv\left\{(m, \gamma) \in \Gamma \mid u\left(c_{0}, y_{0} ; \gamma\right) \geq v(\min \{b, m\}, \gamma)\right\} \\
& v(b, \gamma) \equiv \max _{y} u\left(a-\frac{b}{1+r_{0}}+y, y ; \gamma\right)
\end{aligned}
$$

where $\left(c_{0}, y_{0}\right)$ are the elements of the zero-collection allocation $W_{0}$. Let $\Gamma-\Omega\left(W_{0}\right)$ denote the set of borrowers who prefer either foreclosure or payment in full to FH modification.

Based on this understanding of the behavioral responses to FH, Propositions 5 and 6 show that the FH modification rule is dominated by other modification rules.

\footnotetext{
${ }^{31}$ A borrower with characteristics $\gamma$ has efficient income $=\underset{y}{\arg \max } u\left(a-\frac{b}{1+r_{0}}+y, y ; \gamma\right)$.

${ }^{32}$ Mirrlees (1971) is the classic paper, which had only heterogeneity in persons' ability to produce income. Here the vector $\gamma$ can represent that ability, as well as borrower-specific tastes. Moreover, borrowers in this paper are heterogeneous in yet another dimension: their foreclosure costs.
} 
Proposition 5 If the FH marginal tax rate equals or exceeds $100 \%$ over a non-empty income interval, then there exists a means-tested modification rule satisfying the NPV test that collects more revenue and is more efficient than $\mathrm{FH}$, even while the set of borrowers foreclosed under the rule is exactly the same as under FH.

Corollary The means-tested modification rule that maximizes collections subject to the constraint that it induces foreclosures for exactly the same set of borrowers as does FH has marginal tax rates strictly less than $100 \%$, and induces an allocation that is more efficient.

The full proof is shown in Appendix II, but the strategy of the proof is to start with the zero-collection allocation $W_{0}$ offered by FH and add points to the $[-y, c]$ plane that would: (a) be weakly preferred by some of those modified under the FH rule (formally, borrowers with characteristics $(m, \gamma) \in \Omega\left(W_{0}\right)$ ), (b) have those borrowers pay some part of the unsecured part of their loan (in contrast to FH, which has them pay nothing), and (c) would not be strictly preferred by any borrower not modified under the FH rule. It is possible to add such points because the FH rule features marginal tax rates at least $100 \%$.

The allocation constructed by the proof of the Proposition is more efficient because it permits greater collections, but does not change any borrower's utility: some of the borrowers pay more under the collection-maximizing rule without having lower utility because the income they are induced to supply is closer to their efficient income supply.

In order to prove the corollary, suppose the contrary: the collection-maximizing modification rule had a marginal tax rate that was greater than or equal to $100 \%$ over some range that affects behavior. Then an alternative means-tested modification rule could be constructed, using the same algorithm as the proof of Proposition 5, that collects more and forecloses on exactly the same borrowers: a contradiction. 
Proposition 6 If the FH marginal tax rate equals or exceeds $100 \%$ over a non-empty income interval, then there exists a means-tested modification rule satisfying the NPV test that collects more revenue for lenders, is more efficient than $\mathrm{FH}$, and brings more personal income tax revenue, even while the set of borrowers foreclosed under the rule is exactly the same as under FH.

Proof All modified borrowers under FH earn exactly the minimum income threshold. In order to construct the allocation described in the proposition, follow the algorithm of Proposition 5's proof, but only for incomes that exceed the minimum income threshold. This allocation strictly increases incomes for some borrowers, and leaves the income of all others unchanged. More income earned by borrowers means more personal income tax revenue for the state, local, and federal governments that collect them.

The modification means-tests are based on income reported to the Internal Revenue Service on personal income tax returns, so Proposition 6 notes that the FH guidelines induce borrowers to reduce that reported income, which in term reduces personal income tax collections. A prior economics literature has already shown how tax rates are excessive when multiple collectors have access to the same tax base (Olson, 2000), so it is ironic that the United States Treasury both collects personal income taxes (through the Internal Revenue Service) and further discourages taxpayers to report income on the personal income tax return (through HAMP). Arguably, personal income tax collections would be greater if the Treasury discourage the various debt collectors in the economy from means-testing, rather than encouraging it (Mulligan, 2009).

The above propositions hold constant the identity of borrowers foreclosed. It follows that alternative modification rules can not only collect more and be more efficient than FH, but those same rules would improve any objective that depends on collections, efficiency, the number of foreclosures, and/or the total cost of foreclosures.

As explained in connection with Proposition 3, the FH marginal tax rate on the base year incomes of eligible borrowers depends on the income share target (31\% or $38 \%$, depending on the sponsoring agency), the factors for discounting future mortgage 
payments, and the number of years of payments that are linked to base year income. Arguably, this marginal tax rate is substantially more than $100 \%$ in most cases in which the mortgage is being modified for the last time, so that the Propositions assuming a FH marginal tax rate of at least 100\% apply. Moreover, the conclusions of the propositions may also apply in cases with FH marginal tax rates less than 100\%. For example, Mulligan (2009) places some additional structure on the unobserved heterogeneity among borrowers (still allowing for the possibility that the sensitivity of income supply to incentives is quite small) and obtains a closed-form solution for the income-profile of collection-maximizing marginal tax rates that is fundamentally different from the profile under FH.

\section{Lender Incentives to Expand Modification Capacity}

Three or four million borrowers are thought to be eligible for HAMP's modification, yet observers appear to be frustrated that only about 400,000 modifications occurred under the HAMP program during its first six months (FDIC and other programs changed payments at about the same pace: for about one million mortgages in 2008), ${ }^{33}$ and that borrowers cannot be sure whether they will be ultimately offered a modification (COP, 2009, pp. 48, 71-2). Fewer modifications seem to be occurring than foreclosures proceedings initiated. This situation has been blamed on limited lender capacity to process modifications and the complexity of mortgage ownership (Geanakoplos and Koniak, 2008; COP, 2009, pp. 34, 72), although I show below how the result may be enhanced collections, given the federal guidelines. For some of the same reasons that a fully-enforced FH has undesirable outcomes, it gives lenders little incentive to enforce them.

If lenders really do have a limited modification capacity, that capacity would have to be rationed among eligible borrowers. Here I assume that each eligible borrower in year 1 receives a modification with probability $p$, and has his modification request rejected with probability $1-p$. In the case of rejection, the original mortgage contract is

\footnotetext{
${ }^{33}$ COP (2009, p. 48), and Office of Thrift Supervision (2009a, p. 18). HAMP modifications appear to have occurred at about the same pace for the remainder of 2009 (Luhby, 2010).
} 
followed, including its foreclosure provisions, which means that the borrower is either foreclosed or paying in full according to $\min \{m, b\}$. When each borrower makes his year 0 income supply decision, he knows the modification schedule $x(y)$ for those who will be modified, and knows the magnitude of $p$, but does not yet know his random outcome (whether he will be modified or rejected).

In order to understand the consequences of the capacity constraint, it helps to compare outcomes with $p=1$ ("full enforcement" of the guidelines) to outcomes with $p=$ 0 in the case that the FH marginal income tax rate is at least $100 \%$. As shown above, $p=$ 1 results in only two types of collections: full collection $b$ from borrowers who would rather pay in full than be foreclosed or pass the FH means test, and zero collections from those modified and those foreclosed. ${ }^{34}$ In other words, collections are no greater with $p=$ 1 than if lenders made no modifications ( $p=0$ ), and would be strictly less as long as at least one borrower with $m>b$ would be eligible for a FH modification. Thus, some $p<1$ maximizes collections.

The borrower payoff to earning the minimum income threshold is increasing in $p$ because a borrower earning that threshold is paying $x=0$ with probability $p$ and $\min \{m, b\}>0$ with probability $1-p$. Thus, the higher is $p$, the greater the number of borrowers receiving modification $x=0$, which proves:

Proposition 7 If $M T R \geq 100 \%$, then $p=1$ minimizes collections.

Foreclosures are increasing in the rejection rate $1-p$ by two mechanisms: (1) some of the rejected borrowers opt for foreclosure because they have $m<b$, and (2) the payoff to earning an income in the eligible range is increasing in $p$, and earning an income in that range is the only possibility of preventing foreclosure for a borrower with $m<b$. Despite its adverse effect on total foreclosures, Proposition 7 shows that the capacity constraint increases collections.

A borrower who would be modified under full enforcement is strictly worse off with the capacity constraint, but his loss rises with his foreclosure costs because

\footnotetext{
${ }^{34}$ Recall that, under a fully-enforced FH modification rule, borrowers respond by earning exactly the minimum income threshold, where the NPV test binds.
} 
foreclosure is one possible result of a rejected application for modification. As a result of the capacity constraint, a high foreclosure cost borrower is less willing than an otherwise similar borrower with low foreclosure costs to alter his income to put it in the FH eligible range. In other words, at the expense of additional foreclosures, the capacity constraint helps lenders separate those borrowers who are willing to pay in full from those who are not. Lenders that care about only collections have no incentive to expand their modification capacity, so the fact that so many eligible mortgages have not yet been modified may not merely be the result of administrative snafus. ${ }^{35}$

My proof of Proposition 7 relied on the FH marginal tax rate's being large enough to, under full enforcement, attract a number of borrowers to the zero collection point, but that MTR might still be less than $100 \%$. In fact, even the means-tested modification rule that maximizes collections under full-enforcement may collect less than would a meanstested modification rule that is to be randomly applied. To see this, note that even the collection-maximizing rule has a range of incomes in which the modifications are generous enough that little is collected in that range as compared to collections from those with greater incomes. If these collections are small enough, lenders would collect more by randomly rejecting modifications from borrowers earning in that range - thereby losing collections from those who are ultimately foreclosed as a result of the rejection in order to discourage other borrowers from reducing their incomes in order to qualify for the most generous modification.

For a given means-tested modification rule, incomes under modification capacity constraints are less distorted than they would be if the rule were fully enforced, because the marginal tax rate is $p^{*} M T R$ rather than $M T R .^{36}$ Thus, while a capacity constraint increases foreclosures under $\mathrm{FH}$, it decreases the program's income distortion and may ultimately increase efficiency. ${ }^{37}$ Conversely, even if it were observed that the $\mathrm{FH}$ programs actually induced only a few borrowers to adjust their incomes in order to

\footnotetext{
${ }^{35}$ HAMP also offers modification subsidies, so that in reality lenders likely care about the sum of collections and subsidies. I add a modification subsidy to the model below.

${ }^{36}$ The means-tested rule that maximizes collections under random enforcement may also have a smaller MTR than the rule that maximizes collections under full enforcement because the foreclosure-cost separation achieved by randomization may reduce the foreclosure cost separation that can be achieved by means-testing.

${ }^{37}$ Perhaps this is why lenders often do not publish debt forgiveness formulas, and the Treasury itself has been secretive about the NPV test (COP, 2009, p. 47) that determines the zero-collection point.
} 
become eligible for a modification, it is still possible that many borrowers would have adjusted if they had anticipated the modification rules to be fully enforced.

The "small" number of modifications occurring during 2008 under the FDIC program prompted the Obama administration to allocate about $\$ 75$ billion, or about $\$ 20,000$ per mortgage, for subsidies to mortgages modified under the HAMP program. Depending on how these subsidies are incorporated in the NPV test, and the administrative costs involved, a lender may or may not profit from a borrower who locates at the zero-collection point, which helps determine whether the lender can profit from randomly foreclosing on eligible borrowers. ${ }^{38}$ But the existence of the subsidy does not change the fact that the FH target income share and NPV test create terrible incentives for borrowers to supply income and for lenders to expand their capacity to modify mortgages.

\section{Conclusions}

With the intentions of preventing foreclosures and strengthening the financial system, the FDIC and the U.S. Treasury have created guidelines for modifying mortgages, and require that the guidelines be followed for a large class of mortgages. The guidelines include an income share target (for housing expenditures), a NPV test, and voluntary participation by borrowers. This paper shows how the facts that actual modifications do little to reduce principal, are still outnumbered by foreclosures, and add to borrower uncertainty, may result from incentives created by those very guidelines.

Through their income share target and "NPV test," the federal modification programs have manufactured a tradeoff between the number of foreclosures prevented in the short term and the durability of those foreclosure prevention efforts, because they make it impossible to both write down principal and offer modification to a wide range of borrowers. Another consequence of this tradeoff is to reduce collections, increase foreclosures and their costs, and reduce efficiency as compared to alternative meanstested mortgage modification rules.

\footnotetext{
${ }^{38}$ COP (2009, p. 71) suggests that the subsidy is about of the same magnitude as the costs of administration and redefault.
} 
In many instances the programs create implicit marginal income tax rates in excess of 100 percent, and sometimes as large as 400 percent. One might expect a lot of income to be destroyed (or at least detoured off personal income tax returns where lenders might see them: see Feldstein, 1999) in an economy where millions of people faced such massive marginal income tax rates, but, for two reasons, this paper does not investigate this possibility. First, reasonable people can debate the degree to which the supply of income responds to marginal tax rates, but resolving this debate is unnecessary for proving any of the results of this paper. Even if the supply of income were fully exogenous - that is, failed to respond even a small amount to marginal tax rates in excess of 100 percent - several of my results still hold. Second, under the weak assumption that borrowers cannot be expected to perennially locate at points of their budget sets that are strictly dominated by tens of thousands of dollars, lenders who want to enhance collections will take steps to foreclose on borrowers who are deemed modificationeligible by the federal programs. These steps will dull (but probably not eliminate) the otherwise stark incentives for borrowers to reduce their incomes in order to be eligible for a generous modification, and thereby result in an income distribution impact of the programs that is less than it would be had the guidelines been followed literally.

The fact that foreclosures continue to outnumber modifications almost two years after federal initiatives began has been blamed on complex legal relationships among mortgage owners, and on administrative snafus. ${ }^{39}$ These factors may contribute to the relatively slow pace of modification, but, even without them, the federal programs' income share target automatically frustrates their foreclosure prevention goals, thanks to the strong economic incentives the income share target presents to borrowers and lenders. The same economic analysis explains why the federal guidelines discourage principal reductions (in favor of interest deductions) because principal reductions under the guidelines are consistent with only a narrow eligible income range, and implicitly impose marginal tax rates as large as 400 percent.

\footnotetext{
${ }^{39}$ Eggert (2007), Geanakoplos and Koniak (2008) observe that modifications are difficult for servicers, citing excessive transaction costs in dealing with investors who have varied stakes in the mortgage payments. On the other hand, Foote et al (2009) observe that most servicers are permitted to modify loans. Foote et al (2009) even find that the propensity to modify mortgages is uncorrelated with whether the mortgages are owned by the servicer. Others have interpreted the federal guidelines as a "safe harbor" that would give servicers more freedom to pursue a modification, rather than none. For a description of some of the administrative hurdles, see COP (2009, pp. 34, 72).
} 


\section{Appendix I: Marginal Tax Rates with Various Horizons and Discount Rates}

The marginal income tax rate for incomes in the modification-eligible range depends on the modification horizon (the number of years in which payments will be reduced below the amount specified in the original mortgage contract) and on the rates for discounting future cash flows. For the loan's final modification, the modification horizon is at least five years, and may be as long as the loan's remaining term. A five year modification horizon applies when payment reductions are achieved exclusively by reducing interest, and the interest reduction is small enough that it can fully revert to the originally contracted amount in year six. Typically, "small enough" means that the rate of interest does not have to jump more than one point from year five to year six (U.S. Treasury, 2009b).

Interest reductions that are somewhat larger will impact payments in year six too, reductions that are larger still will impact payments through year seven, etc. (here I assume that the final payment of the loan occurs in year $M>8$, so that there are payments beyond year 5 to be impacted). For example, if the originally contracted interest rate were $6 \% / y r$ and an interest rate of $2 \% / y r$ were required to meet the income share target, then the interest rate would be $3 \% / y r$ in year six, $4 \% / y r$ in year seven, $5 \% / y r$ in year eight, and then back to the originally contracted $6 \% / y r$ in year nine. For this reason, the budget constraint shown in Figure 1 would more accurately be drawn as convex between allocations $Y$ and $W_{0}$. Closest to allocation $Y$, the slope is $\mu R_{5} /\left(1+r_{0}\right)-1$, but, moving toward allocation $W_{0}$, the slope steps up to $\mu R_{6} /\left(1+r_{0}\right)-1$, then to $\mu R_{7} /\left(1+r_{0}\right)-1$, and then to $\mu R_{8} /\left(1+r_{0}\right)-1$. HAMP has a interest rate floor of $2 \% / y r$, so (if the NPV test still passes) further payment reductions would be achieved by principal reductions, thereby making the slope $\mu R_{M} /\left(1+r_{0}\right)-1$ nearest the zero collection point $W_{0}$. Thus, the budget constraint between $Y$ and $W_{0}$ can be piecewise linear with as many as five segments and all but one of those segments of equal width in the income dimension.

Note that, under the weak assumption that allocation $Y$ lies below the zero collection point, a convex budget constraint is observationally equivalent to the linear segment $Y W_{0}$ drawn in Figure 1 - even if some of the segments between $Y$ and $W_{0}$ slope down, because in both cases all points between $Y$ and $W_{0}$ are strictly dominated by the zero collection point. Assuming that the mortgage is enough under water that all five 
segments appear, the average marginal tax rate between $Y$ and $W_{0}$ is greater than $0.5 \mu\left(R_{6}+R_{7}\right) /\left(1+r_{0}\right)$, which is 163 percent if cash flows are discounted at $6 \% / y r$.

Some borrowers will earn more in year zero than they otherwise would in order to reach the zero collection point, and others would earn less. Those earning less would be reducing cash flows in year zero in order to increase them in years $1-5$ and perhaps beyond, which is one reason a borrower might have a higher (one year) rate for discounting cash flows backward from year 1 than he would from years further in the future. Year 0 is likely a recession year - perhaps characterized by tight credit for some borrowers, which is another reason why some borrowers might have high one year cashflow-discount-rates in the early years of the modification, as compared to later years. This appendix therefore considers one year cash-flow-discount-rates that are initially (discounting year 1 to year 0 ) high, and then decline linearly reaching 6 percent by year 5 (a multi-year discount factor is the product of each of the corresponding one year discount factors). Figure 4 shows marginal income tax rates $\mu R_{M} /\left(1+r_{0}\right)$ as a function of modification horizon $M$ in four cases that differ according to the initial one year cashflow-discount-rate. In essentially every case, $\mu R_{M} /\left(1+r_{0}\right)$ exceeds $100 \%$. 


\section{Appendix II: Proof of Proposition 5}

For a FH modified borrower $(m, \gamma) \in \Omega\left(W_{0}\right)$, let $C\left(y ; \gamma, W_{0}\right)$ denote his indifference curve at the modified allocation:

$C\left(y ; \gamma, W_{0}\right) \equiv \min c \quad$ s.t. $\quad u(c, y ; \gamma)=u\left(c_{0}, y_{0} ; \gamma\right)$

If $C$ is empty for a given $y$, I set $C\left(y ; \gamma, W_{0}\right)$ to $\infty$. Adding the point $(-y, c)$ to the FH budget set would change the behavior of a borrower with characteristics $(m, \gamma) \in \Omega\left(W_{0}\right)$ if and only if

$c \geq C\left(y ; \gamma, W_{0}\right)$

For a borrower $(m, \gamma) \notin \Omega\left(W_{0}\right)$ who prefers either foreclosure or payment in full to FH modification, let $U\left(y ; m, \gamma, W_{0}\right)$ denote his indifference curve at the unmodified allocation:

$U(y ; m, \gamma) \equiv \min c \quad$ s.t. $\quad u(c, y ; \gamma)=v(\min \{b, m\}, \gamma)$

If $U$ is empty for a given $y$, I set $U(y ; m, \gamma)$ to $\infty$. Let $E\left(y ; W_{0}\right)$ denote the lower envelope of all borrowers' $C$ and $U$ :

$E\left(y ; W_{0}\right) \equiv \min _{(m, \gamma) \in \Gamma}\left\{C\left(y ; \gamma, W_{0}\right), U\left(y ; m, \gamma, W_{0}\right)\right\}$

Proposition If the $\mathrm{FH}$ marginal tax rate equals or exceeds $100 \%$ over a non-empty income interval, then there exists a means-tested modification rule satisfying the NPV test that collects more revenue and is more efficient than $\mathrm{FH}$, even while the set of borrowers foreclosed under the rule is exactly the same as under $\mathrm{FH}$.

Proof Consider the modification rule $x(y)=\min \left\{\left(1+r_{0}\right)\left[a+y-E\left(y ; W_{0}\right)\right], b\right\}$. Those borrowers not contributing a point to the envelope $E$ strictly prefer the allocation they have under FH than the modification rule $x(y)$. Those who would be modified under FH and (weakly) prefer a different point on $x(y)$ can be both modified and induced to make payments with strictly positive value $\left(1+r_{0}\right)(a+y-E)$. Those who would not be modified under $\mathrm{FH}$ and (weakly) prefer a different point on $E$ can be induced to behave the same as under FH (which is either foreclosed or paying in full). 


\section{Fig 1. Budget Set Induced by FDIC-HAMP Means-Tests}

The horizontal axis measures borrower income during the base year, from highest to lowest. $a$ denotes the present value of future income available for all other goods and paying the unsecured amount of the mortgage (discounted to the base year), $b /\left(1+r_{0}\right)$.

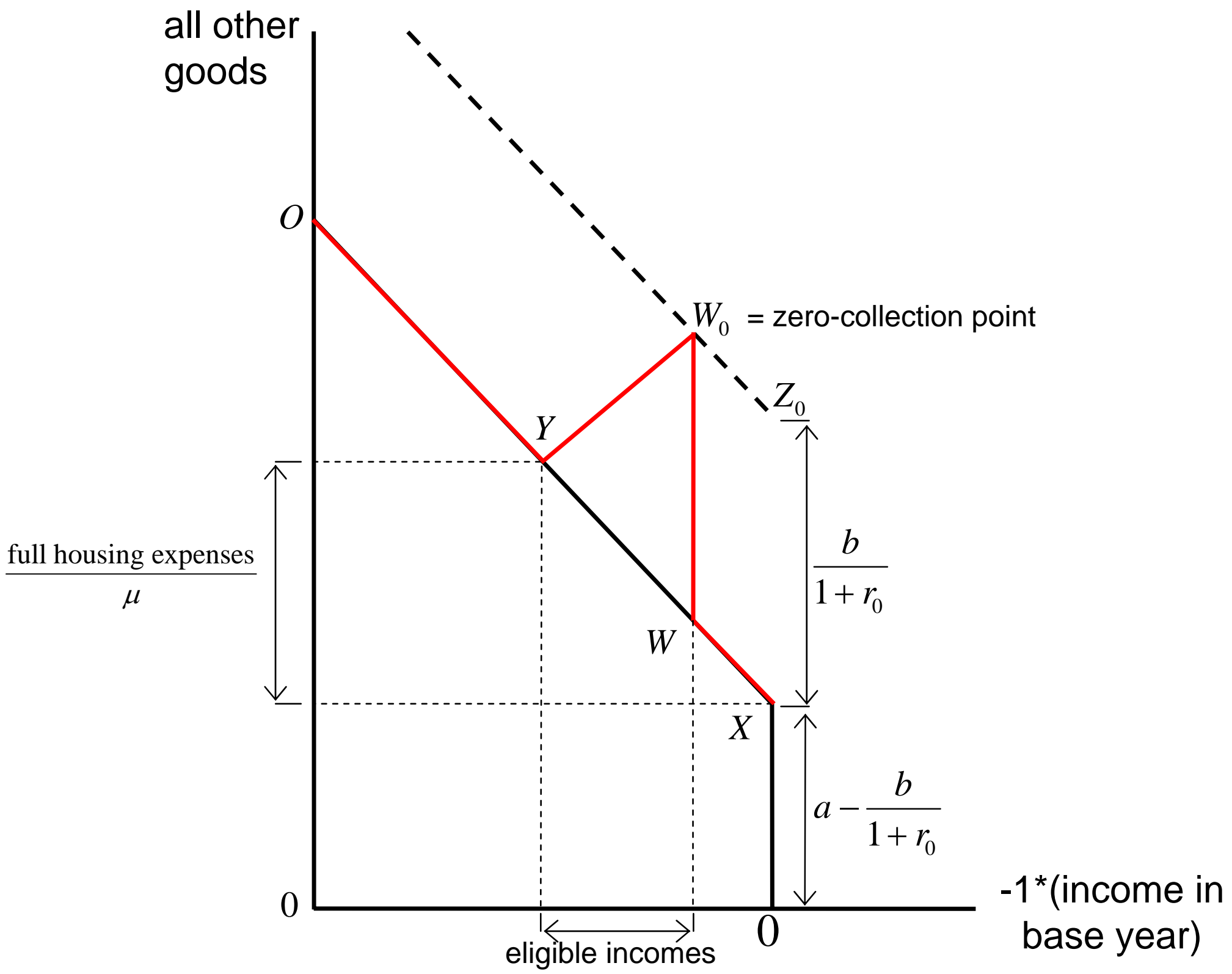




\section{Fig 2. The Marginal Tax Rate and the Eligible Income Range}

The horizontal axis measures borrower income during the base year, from highest to lowest. $a$ denotes the present value of future income available for all other goods and paying the unsecured amount of the mortgage (discounted to the base year), $b /\left(1+r_{0}\right)$. Allocation $W_{0}\left(W_{1}\right)$ is feasible with the lower (higher) marginal tax rate, as with modifications made via interest (principal) reductions.

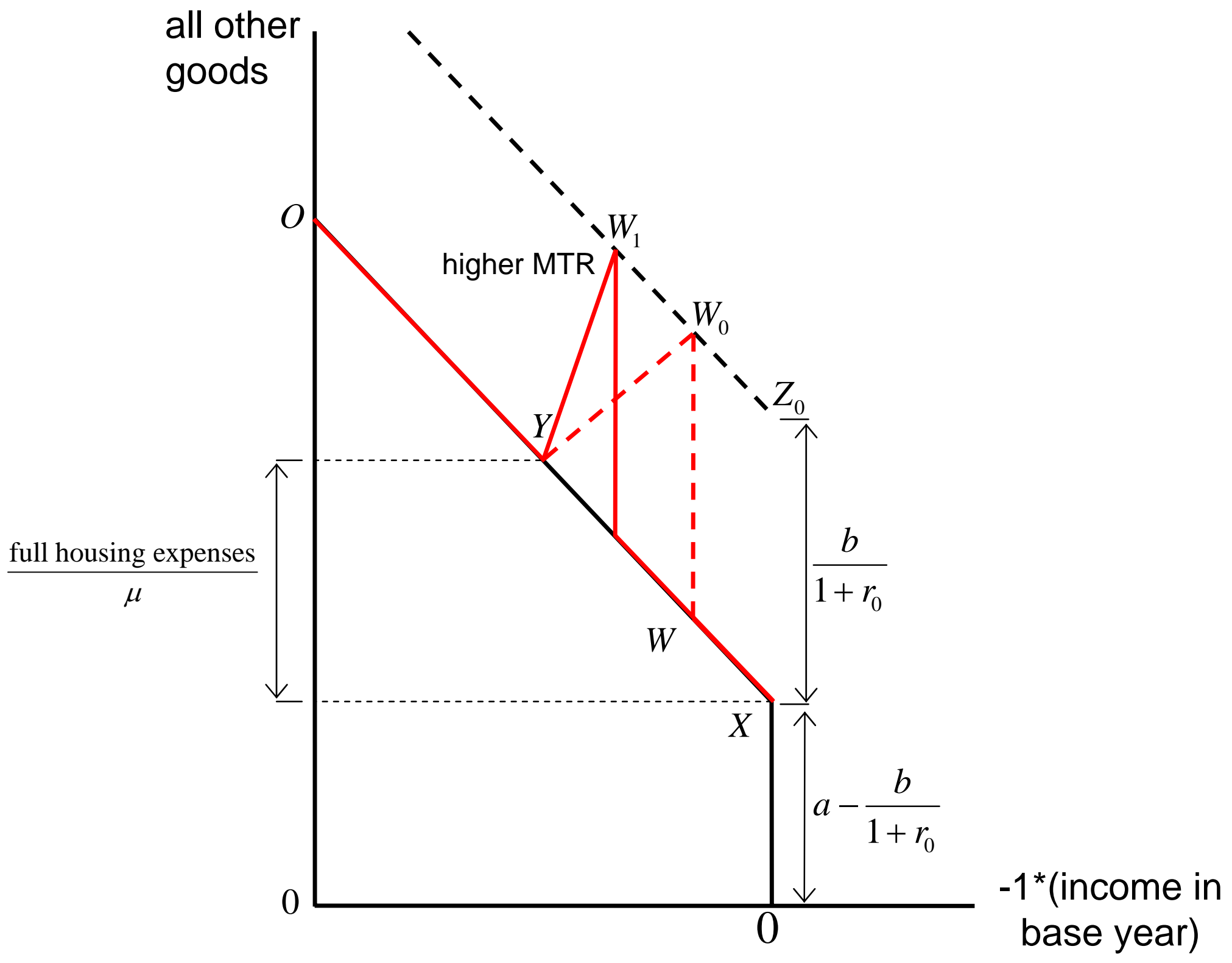


Fig 3. Borrowers' "Demand" for Repayment

The monotone curve graphs the foreclosure cost inverse CDF, from highest cost to lowest.

\section{Foreclosure cost,} repayment amount

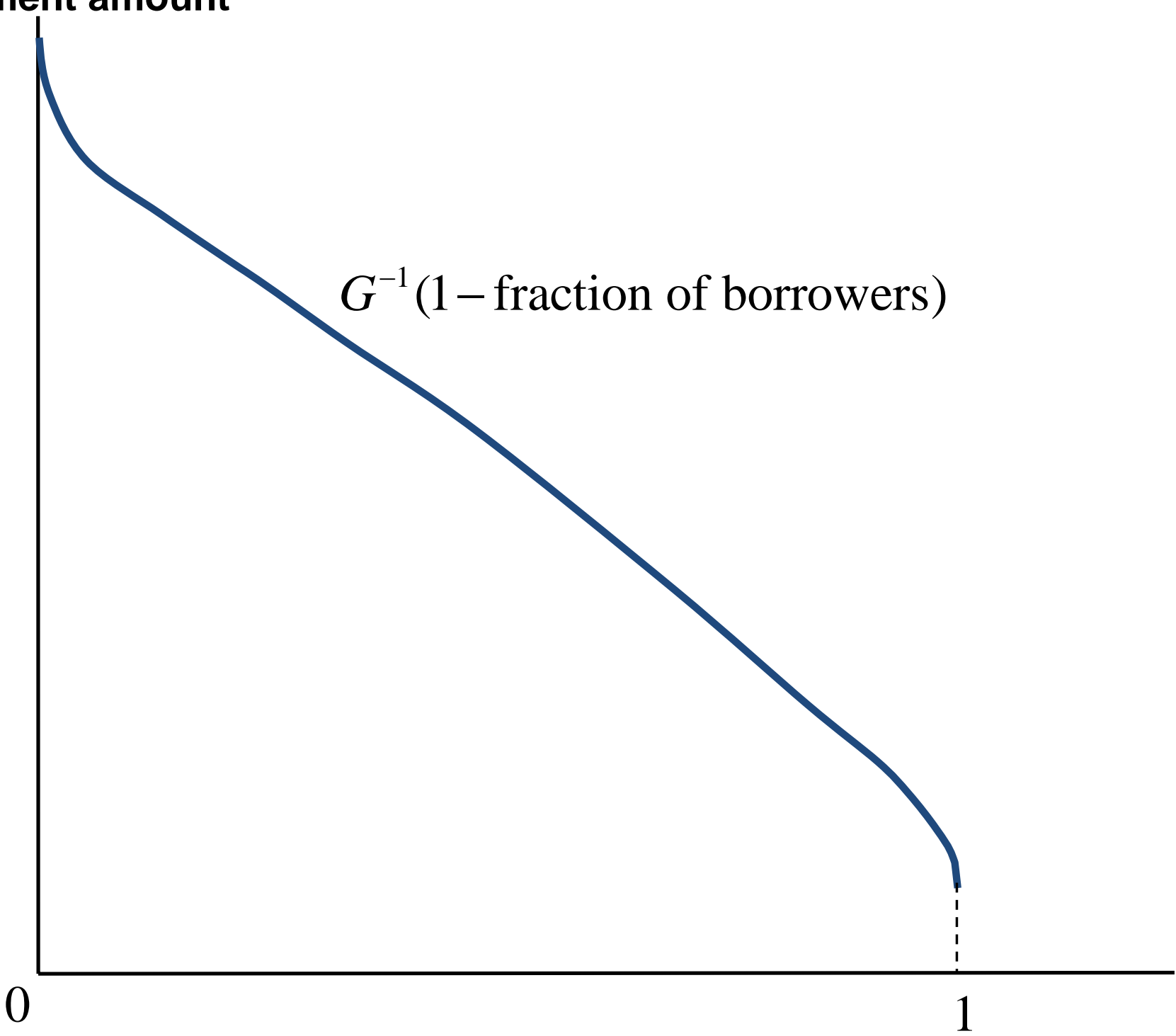

Fraction of borrowers with greater cost 
Fig 4. Marginal Income Tax Rate versus Modification Horizon, Various Initial Interest Rates (share target $=\mathbf{3 1 \%}$ )

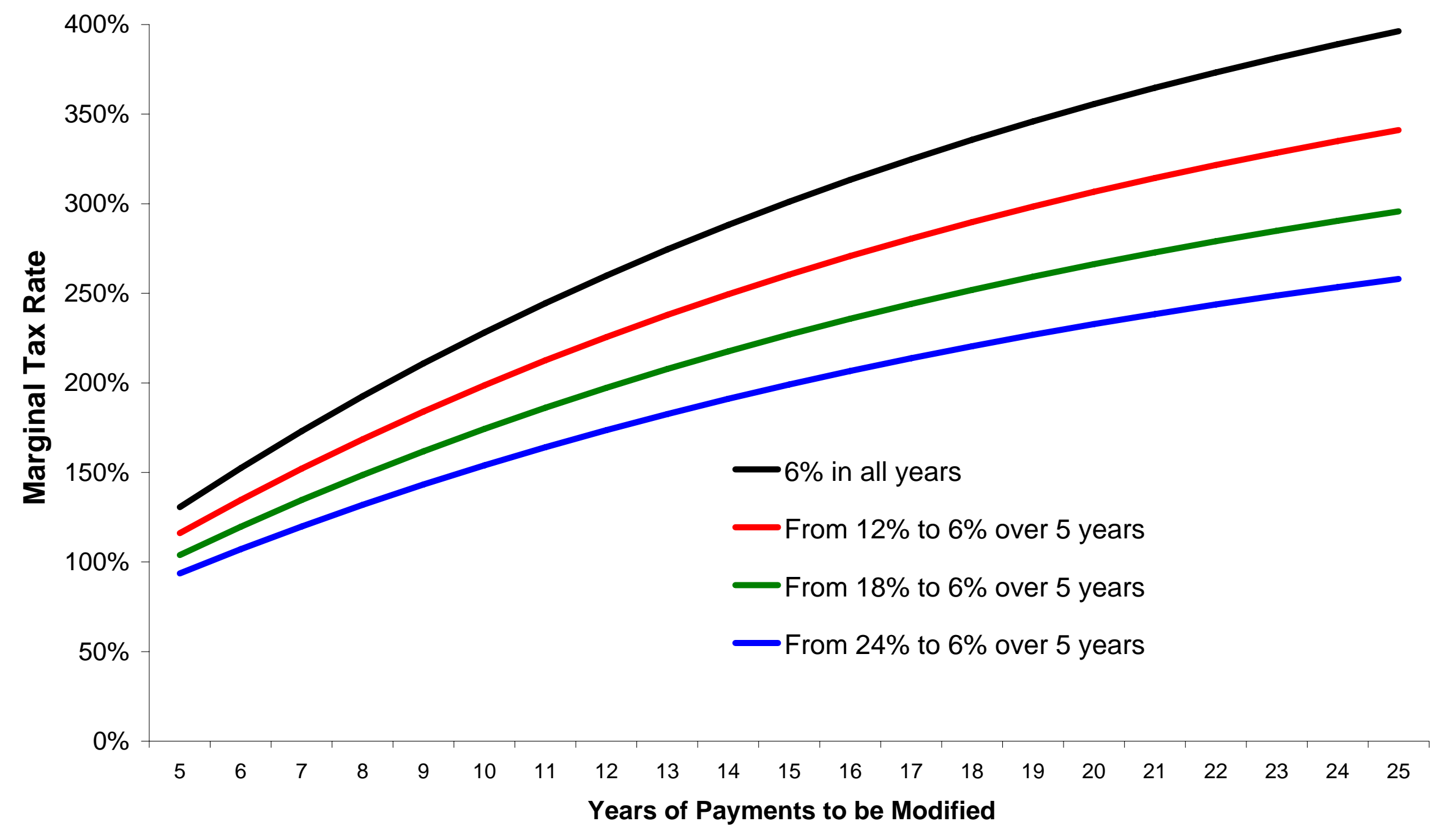




\section{References}

Aversa, Jeannine. “Government Plans Massive Citigroup Rescue Effort.” Associated Press. November 24, 2008.

Bernanke, Ben S. "Nonmonetary Effects of the Financial Crisis in the Propagation of the Great Depression.” American Economic Review. 73(3), June 1983: 257-276.

Congressional Oversight Panel. “October Oversight Report: An Assessment of Foreclosure Mitigation Efforts After Six Months.” October 9, 2009.

Eggert, Kurt. "Comment on Stegman et al's Preventive Servicing." Housing Policy Debate. 18(2), 2007.

Federal Deposit Insurance Corporation. “Loan Modification Program for Distressed Indymac Mortgage Loans.” August 20, 2008a. http://www.fdic.gov/consumers/loans/modification/indymac.html

Federal Deposit Insurance Corporation. “FDIC Loan Modification Program.” November 2008b.

Federal Deposit Insurance Corporation. “FDIC Loan Modification Program Overview.” March 6, 2009. http://www.fdic.gov/consumers/loans/loanmod/ loanmodguide.html

Feldstein, Martin. “Tax Avoidance and the Deadweight Loss of the Income Tax.” Review of Economics and Statistics. 81(4), November 1999; 674-680.

Foote, Christopher, Gerardi, Kristopher and Paul Willen. "Negative Equity and Foreclosure: Theory and Evidence.” Journal of Urban Economics. 64, 2008: 345-245.

Foote, Christopher, Gerardi, Kristopher, Lorenz Goette, and Paul Willen. "Reducing Foreclosures: No Easy Answers.” NBER working paper \#15063, June 2009.

Geanakopolos, John D. and Susan P. Koniak. “Mortgage Justice is Blind.” New York Times. October 30, 2008.

Geanakoplos, John D. and Susan P. Koniak. “Matters of Principal.” New York Times. March 4, 2009.

Grochulski, Borys. “Optimal Personal Bankruptcy Design: A Mirrlees Approach.” Richmond Federal Reserve Working paper No. 08-5, September 2008. 
Gruber, Jonathan and David A. Wise, eds. Social Security Programs Around the World. Chicago: University of Chicago Press (for NBER), 2007.

Han, Song and Wenli Li. "Fresh Start or Head Start: The Effects of Filing for Personal Bankruptcy on Work Effort.” Journal of Financial Services Research. 31, 2007: 123-152.

Kahn, Charles and Abdullah Yavas. "The Economic Role of Foreclosures." Journal of Real Estate Finance and Economics. 8, 1994: 35-51.

Legal Services of Northern California. "California Guide to the Food Stamp Program: Prospective Quarterly Budgeting.” 2008. http://www.foodstampguide.org/prospective-quarterly-budgeting/

Leibowitz, Stan. "New Evidence on the Foreclosure Crisis." Wall Street Journal. July 3, 2009, page A13.

Levy, Dan. "U.S. Underwater Mortgages May Reach 30 percent, Zillow Says.” August 11, 2009. http://www.bloomberg.com/apps/news?pid=20601103\&sid=a2p_zMYkFQFg

Livshits, Igor, James McGee and Michele Tertilt. "Consumer bankruptcy: a fresh start.” American Economic Review. 97(1), March 2007: 402-418.

Luhby, Tami. "States Urge Action on Foreclosures." January 20, 2010. http://money.cnn.com/2010/01/20/news/economy/state_foreclosure_prevention/in dex.htm

Mirrlees, James A. “An Exploration in the Theory of Optimum Income Taxation.” Review of Economic Studies. 38(114), April 1971: 175-208.

Moffitt, Robert A., ed. Means-Tested Transfer Programs in the United States. Chicago: University of Chicago Press (for NBER), 2003.

Mulligan, Casey B. "Means-tested Mortgage Modification: Homes Saved or Income Destroyed?” NBER working paper no. 15821, August 2009.

Neighborhood Legal Services Association. "Food Stamps." July 27, 2009. http://www.nlsa.us/legal_information/benefits/pb7_food_stamps_overview.htm

Office of Thrift Supervision. "OCC and OTS Mortgage Metrics Report. Fourth Quarter 2008.” April 2009a.

Office of Thrift Supervision. "OCC and OTS Mortgage Metrics Report. Third Quarter 2009.” December 2009b. 
Olson, Mancur. Power and Prosperity. Oxford: Oxford University Press, 2000.

United States Department of Treasury. "Homeowner Affordability and Stability Plan: Executive Summary.” February 2009a.

United States Department of Treasury. "Homeowner Affordability Modification Program Guidelines.” March 2009b.

United States Department of Treasury. "Homeowner Affordable Modification Program: Introduction.” 2009c.

White, Michelle and Ning Zhu. "Saving Your Home in Chapter 13 Bankruptcy.” NBER Working Paper no. 14179, July 2008. 